\title{
MANIPULAÇÃO E PARTITURA VOCAL: O TRABALHO DE INTERPRETAÇÃO DO PERSONAGEM "SANCHO PANÇA"
}

\author{
Saulo Germano Sales Dallago ${ }^{1}$ (Doutor) \\ sauloator@uol.com.br
}

O Teatro de Formas Animadas compreende uma vasta gama de possibilidades estéticas, tanto no que diz respeito à concretude dos materiais propriamente dita, utilizados para a confecção dos objetos manipulados, quanto na proposta visual que envolve a tessitura destas formas animadas e, num último momento, a direção que se dará ao espetáculo, envolvendo outros elementos como cenografia, iluminação, música e/ou sonoplastia e, claro, a própria interpretação do ator, responsável por animar a forma deste tipo de teatro, dando-Ihe movimentação e voz.

Pensando em todos estes aspectos, este estudo pretende, com ênfase nas relações manipulação/interpretação vocal, descrever o processo de construção da interpretação do personagem Sancho-Pança, um boneco de balcão protagonista do espetáculo $O$ Grande Governador da Ilha dos Lagartos, entremez de Antônio José da Silva (O judeu) extraído da ópera Vida do grande D. Quixote de la Mancha e do Gordo Sancho Pança, apresentada pela primeira vez no ano de 1733 em Lisboa. O texto do espetáculo foi adaptado e traduzido pelos professores David Cranmer, da Universidade Nova de Lisboa, Ana Guiomar Rêgo Souza e Robervaldo Linhares, colegas da Escola de Música e Artes Cênicas (EMAC) da UFG, e a direção musical ficou a cargo do também professor e maestro Carlos Costa. Além destes, o espetáculo teve como diretor geral/teatral o professor Kleber Damaso Bueno, além de outro colega, principal responsável pela confecção dos bonecos e adereços a serem utilizados no espetáculo e o único dentre todos com experiência em teatro de manipulação de formas animadas,

1 Graduado em Artes Cênicas Bacharelado - Interpretação Teatral (UFG, 2005), Mestre (UFG, 2007) e Doutor (UFG, 2012) em História. Professor da Escola de Música e Artes Cênicas da UFG, junto aos cursos de Teatro e Direção de Arte, na cadeira de Produção Cultural e Teorias do Teatro, desde o ano de 2010. 
o professor Francisco Guilherme de Oliveira Júnior, também companheiro de trabalho nos cursos de Artes Cênicas e Direção de Arte da EMAC.

As relações entre a construção da personagem Sancho Pança e vários outros elementos cênicos, como a dramaturgia, a cenografia, as músicas executadas pela orquestra e as canções interpretadas ao vivo serão foco de observação deste trabalho, que tem como objetivo relatar o percurso desde os primeiros contatos com o boneco supramencionado, passando pelas leituras dramáticas do texto adaptado, até a incorporação do texto à manipulação e a elaboração final de algumas cenas específicas do espetáculo. A relevância desta pesquisa se liga principalmente ao ineditismo desta produção, nacionalmente falando, uma vez que a mesma congregou diversas linguagens artísticas, como teatro de formas animadas, música e canto.

O teatro de formas animadas, ou teatro de animação, segundo nomenclatura alcunhada por Ana Maria Amaral (2007), compreende várias possibilidades do ponto de vista estético, como máscaras, sombras, objetos, bonecos, marionetes, entre outros, daí porque chamá-lo, como tradicionalmente fazia-se, de Teatro de Bonecos, acaba sendo uma forma reducionista de se referir à tamanha gama de manifestações. O importante, ao abordar este tipo de teatro, é compreender sua relação com o inanimado, abrangendo desde as representações do cotidiano humano até ideias abstratas e formas simbolicamente expressas através destes objetos e/ou formas.

Diante do acima exposto, pontuarei algumas etapas do processo de construção da interpretação do boneco Sancho Pança, a partir de experimentações cênicas, relações com outras linguagens da cena e orientações repassadas pelo professor Francisco Guilherme que, como mencionado acima, era então a única pessoa com domínio da linguagem de formas animadas dentre aqueles que compunham a equipe de produção de O Grande Governador da Ilha dos Lagartos.

Em meados de abril de 2014, fui convidado a integrar a montagem e escolhido para dar vida ao protagonista da mesma, o já mencionado Sancho Pança. Ao ser 
apresentado ao boneco, logo algumas características chamaram-me bastante atenção como, por exemplo, o rosto, que possuía uma expressão bastante significativa quanto à sua personalidade: boca entreaberta, leve sorriso, olhos grandes e maçãs do rosto salientes, além de uma cabeça avantajada em relação ao restante do corpo. Segundo o professor Guilherme informou-me, tratava-se de um boneco de balcão, por ter atrás de sua cabeça um gancho que permitia segurá-lo com uma das mãos e, com a outra, poder manipular suas pernas e braços (conversa com o autor, abril de 2014). Aliás, não só o boneco Sancho, mas todos os outros bonecos do espetáculo também possuíam as mesmas características de manipulação, apenas diferindo levemente em relação ao peso e tamanho, além, é claro, das características físicas gerais. Foram construídos a partir de isopor, sendo revestidos com papel e cola. Fitas de pano compunham suas articulações, e todos possuíam também vestimentas a partir de diferentes tecidos, bem como cabelos a base de fios/linhas. Tinham uma média de 60 a 90 centímetros de altura, em pé.

Sancho (Figura 1) era um boneco que possuía pernas que não se dobravam, mas mantinham um bom ângulo de abertura entre elas, o que permitia certa facilidade na manipulação do caminhar do mesmo, podendo este caminhar ser feito, mesmo com certa dificuldade, apenas utilizando a mão que o manipulava atrás da cabeça. $O$ tronco era um tanto quanto roliço, o que mantinha os braços, assim como as pernas, bem afastados, mas com excelente mobilidade, permitindo ao manipulador bastante liberdade de movimentação, principalmente podendo passar objetos de uma mão a outra do boneco, além de movimentá-los com facilidade pelo espaço.

Logo de início, quando das primeiras tentativas de manipulação do boneco, ficou claro a substancial diferença entre a interpretação comum de personagens, sem a utilização de formas animadas para tal, e na qual eu já tinha uma experiência relativamente grande, e a interpretação com um boneco que, não sendo parte de meu corpo, deveria tornar-se a extensão das ações de mim mesmo, fazendo com que no objeto se mantivesse a minha concentração de atenção e também da plateia, ao contrário da interpretação convencional. Em relação a esta diferença de abordagem, Ana Maria Amaral salienta: 


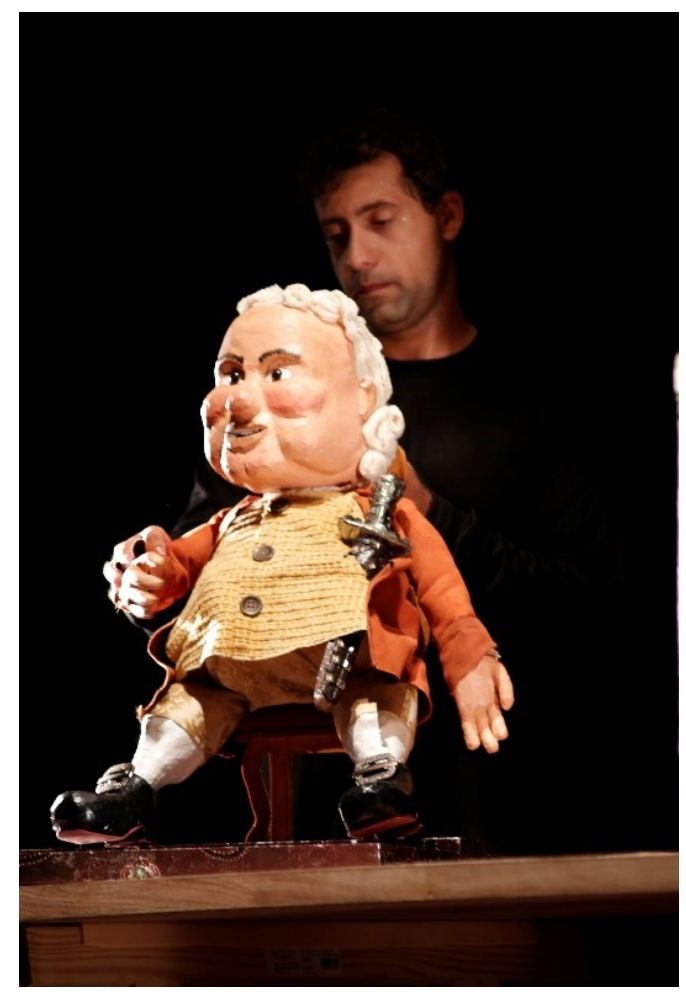

Figura 1 - Sancho Pança e manipulador, apresentação de $O$ Grande Governador da Ilha dos Lagartos no IV Simpósio Internacional de Musicologia em Pirenópolis/GO, 04/06/2014. Créditos: José de Alencar Melo (Zekhety)

$\mathrm{O}$ ator confunde a sua própria imagem com a imagem do personagem. $\mathrm{O}$ ator encarna o personagem. $\mathrm{O}$ ator é visto. Já enquanto ator-manipulador, a sua imagem não é visto. Ou, quando é vista, quando na cena o atormanipulador está visível, sua imagem deve ser uma imagem neutra, nunca a imagem do personagem propriamente. No Teatro de Animação a imagem do personagem é sempre diferente da imagem do ator-manipulador. Todo objeto animado, quando bem manipulado, neutraliza a presença do ator (Amaral, 2007, p. 22).

No início dos ensaios, a primeira coisa que foi orientada pelo professor Guilherme aos atores-animadores foi para que testássemos o caminhar do boneco para que todos pudessem descobrir diversas formas de fazê-lo andar, da forma mais natural possível, e claro, encontrar a melhor dentre elas. O cenário do espetáculo, elaborado pelo professor Kleber, consistia em três portas de madeira, cada uma sobre dois cavaletes, que mudavam de disposição conforme a cena a ser representada, e por onde movíamos os bonecos e todos os outros objetos utilizados nas cenas. Uma das orientações que tivemos foi para que, neste caminhar, mantivéssemos ao máximo 
possível o eixo do boneco, tentando fazer com que o mesmo não perdesse o aspecto humano neste caminhar.

Após diversos testes com a caminhada, partimos para exercícios que envolvessem o olhar do boneco. Isto porque, segundo foi-nos passado pelo professor Guilherme, alguns procedimentos eram padrão para que, em cena, pudéssemos demonstrar as relações estabelecidas. Segundo ele, o boneco que estivesse com a voz deveria procurar olhar mais em direção a plateia e, os demais, virarem seu olhar para este boneco falante. Isto faria com que o público percebesse melhor o foco da cena. Além disso, outro erro bastante cometido por atores sem muita experiência em manipulação era o de, ao invés de fazer com que o boneco olhasse determinado objeto em cena, olhar ele mesmo, ator, para tal objeto.

Paralelamente ao processo de manipulação física dos bonecos, iniciamos também a leitura do texto dramatúrgico do espetáculo. Já traduzido para o português brasileiro, a peça continha ainda diversas expressões de um português mais arcaico, lusitano, o que possibilitou aos atores a construção de uma partitura vocal bastante extra cotidiana, ou seja, diferente daquela usada por nós mesmos no dia-a-dia. Particularmente, o meu personagem era aquele com a grande maioria dos textos do espetáculo, uma vez que, além de estar presente em todas as cenas da peça, tinha como característica a verborragia, o excesso de palavras e frases de efeito, que denotavam, por um lado, seu discurso articulado e sedutor, capaz de enrolar aqueles que o ouviam continuamente por longos períodos, porém, por outro lado, deixava antever a simploriedade do mesmo, em breves trechos onde entregava sua falta de conhecimento jurídico para proferir as sentenças que despachava, enquanto governador, sobretudo na primeira parte do espetáculo, onde o mesmo recebe vários reclamantes com diferentes queixas em seu gabinete e, um a um, vai ludibriando e advogando em interesse próprio a partir das causas trazidas pelos membros do povo. 
Conforme afirma Bueno (2015), diretor do espetáculo, Sancho se utiliza em diversos momentos durante as audiências públicas de uma retórica bastante evasiva, permeada de ambição e corrupção, na tentativa de manutenção do poder a qualquer custo. O uso da palavra, tanto para impor autoridade quanto para desviar a atenção de seus reclamantes durante o diálogo, está sempre a serviço da corrupção e vulgarização do conceito de justiça. Há uma alternância entre o comer e o falar, ou seja, entre a gula e a retórica, usando a segunda como uma espécie de arma para satisfação da segunda.

Essa, aliás, foi uma das características que mais se destacou no processo de construção da oralidade do personagem Sancho Pança: sua capacidade de, a partir de frases de efeito excessivamente longas e explicativas, construir uma imagem de (pseudo) intelectual e, assim, se não angariar a admiração da população, uma vez que fica claro o descontentamento das pessoas em relação aos julgamentos do governador, ao menos construir uma imagem de líder atencioso, ao se dedicar a ouvir e responder as queixas do povo e, sorrateiramente, alcançar ganhos pessoais através destas demandas. Se a palavra tem poder, e quem possui o dom da eloquência e retórica controla muito bem as palavras, Sancho Pança sustenta-se no poder graças ao uso que faz destas palavras, até, neste sentido, por preencher em muitos momentos o espaço que poderia se tornar a oportunidade de maiores reclamações por parte dos cidadãos que atende com sua excessiva emissão de vocábulos, não permitindo assim a plena expressão da voz do povo.

O boneco tinha um corpo volumoso, além de um rosto largo com bochechas salientes, imprimindo-lhe um ar gordo e bonachão. Esta fisicalidade do boneco trouxeme a ideia da construção de uma partitura vocal com registro mais grave, voz empostada, fala com ritmo levemente devagar, passando um ar de mansidão, tranquilidade, mas com alguns momentos de maior força e rispidez, principalmente em trechos onde o mesmo se impacientava ou dava ordens. Como já mencionado, as palavras rebuscadas e expressões não usuais contribuíram para a construção desta vocalidade, além das intenções do personagem em ludibriar seus ouvintes através do discurso, tornando a fala do boneco preenchida por um excesso verbal que ia se construindo de forma lenta e calculada. 
Em relação ao conteúdo e forma vocais, na construção da partitura vocal para a cena, podemos inferir que:

\begin{abstract}
a voz é expressão indissolúvel de conteúdo e forma, quer dizer: o que é dito está estruturalmente conectado ao como é dito. Se por um lado a forma traz consigo um conteúdo, por outro lado o conteúdo subsiste numa forma determinada, permitindo a sua eficácia (IRLANDINI, 2013, p. 25).
\end{abstract}

Neste viés, o conteúdo do que era dito por Sancho Pança, ou seja, um excesso de palavras floreadas, longas explicações e prolixidade, aliava-se também à forma com que estas informações eram emitidas, através de um falar pomposo, altivo e seguro, embora um ouvido mais atento conseguisse facilmente captar as incongruências contidas em seu discurso, sendo este um dos aspectos que ressaltavam a comicidade da personagem. Concomitantemente, seguia o processo de construção gestual do boneco que, exatamente por falar demais, precisava, em muitos momentos, ser econômico em relação às suas ações físicas. Esta problemática, presente no Teatro de Animação, pode ser também observada quando refletimos sobre o teatro convencional, onde, dependendo da proposta cênica apresentada pelo diretor do espetáculo, a economia gestual precisa ser algo bastante presente nas ações dos atores. Lançando nosso olhar ao início do século XX, veremos o desenvolvimento, no teatro russo, de uma estética simbolista para a cena que, principalmente através das encenações de Vsevolod Meierhold, primaram por vezes por um grande controle gestual na interpretação dos atores, aproximando-os, inclusive, da imagem de marionetes, conforme podemos observar a partir da citação a seguir:

\footnotetext{
O ator simbolista prenunciava o surgimento do ator moderno. O caminho empreendido por Meierhold, predominantemente visual e estilizado, revelava, no corpo estático do ator, ora um caráter pictórico, ora um caráter escultural. A recriminação da submissão do ator ao encenador, que o transformava em "marionete", não é infundada. A privar o ator do gesto vivo, realístico, ao impor uma entonação "artística", ao invés da entonação lógica, Meierhold se distanciou da reprodução da vida na cena (THAIS, 2009, p. 35).
}

Todavia, em alguns momentos específicos do espetáculo, a questão gestual do boneco tornou-se o foco maior das atenções, principalmente quando o diálogo entre a forma animada se dava de maneira mais direta com a parte musical do espetáculo o que, não obstante, também interferiu na composição da partitura vocal do mesmo. 
Para exemplificar esta afirmação, farei uso de um momento da encenação que conjugou na cena, ao mesmo tempo, a manipulação, a música e o canto.

Para melhor entendimento da estrutura da peça $O$ Grande..., podemos dividi-la em duas partes, ou atos, como é a nomenclatura usual no teatro. O primeiro, como já descrito, acontece no gabinete de Sancho Pança onde o mesmo recebe vários cidadãos que veem buscar o auxílio do governador na solução de problemas. O segundo ato passa-se na casa da câmara, onde é preparado um jantar em homenagem ao governador que, ao longo da cena, vai se configurando na verdade numa espécie de vingança da população contra o poder instituído, uma vez que o protagonista é proibido de se alimentar por dois médicos presentes ao banquete, que alertam ininterruptamente sobre os males que a ingestão de diversos alimentos poderia causar à saúde do líder político.

O momento específico no qual me deterei neste trecho do trabalho ocorreu durante o primeiro ato, ou seja, nas cenas de julgamentos de causas realizados pelo governador. A primeira cena do espetáculo é um solilóquio de Sancho aonde divaga sobre o fato de ter conseguido se tornar governador e, após ela, entra o personagem do Meirinho, espécie de oficial de justiça subordinado ao governador. Na segunda cena, com os dois e ainda sem a presença de nenhum reclamante, o Meirinho inicia um processo de demonstrações cada vez maiores ao longo da peça de sua desconfiança em relação à capacidade do governante em exercer a função de chefe de estado. Nesta segunda cena, após declarar ao empregado público seu desejo em alterar o nome da ilha de Ilha dos Lagartos para Ilha dos Panças, há a execução de uma ária, durante a qual um cantor, interpretado pelo aluno do curso de música Félix Bauer, aparece em cena ao lado da mesa/balcão sobre a qual encontrava-me com o boneco, utilizando-se de uma máscara com suporte (não fixa) exatamente igual ao rosto de Sancho Pança, e canta uma canção que tem como tema a vontade do protagonista em realizar a alteração de nomenclatura supramencionada. 
Nesta cena, o cantor assume a voz do personagem Sancho Pança que, entretanto, permanece em cena, relacionando-se, através da manipulação por mim executada, com o mesmo. A música contém uma introdução, antes da primeira estrofe cantada por Félix, e dois intervalos, contendo então um total de três estrofes cantadas. $\mathrm{Na}$ direção da cena, o professor Kleber Damaso procurou destacar a paixão do personagem pelo vinho, mesmo porque a música contém trechos como que aja vinho em fartura ou quem quiser se embebedar. Desse modo, tanto na introdução quando nos dois intervalos do canto surgia uma atriz em cena carregando um barril de vinho e dois copos (todos feitos com papelão e cola pelo professor Guilherme), e tanto o boneco quanto o cantor eram servidos pela mesma, para que pudessem ter vinho durante a música que tratava deste mesmo assunto, entre brindes, erguidas de copo e generosos goles.

De acordo com a direção proposta por Kleber, o boneco Sancho deveria, a cada estrofe da música, simular estar também cantando com seus movimentos (Figura 2) e, nos intervalos sem canto, beber e se relacionar com o músico, num processo aonde, cada vez mais, ia adquirindo uma movimentação inexata, simulando, assim, uma embriaguez a partir da generosa quantidade de vinho ingerida. O músico, que trazia a máscara numa das mãos, colocava-a sobre o rosto a cada um destes intervalos sem canto, igualando sua figura à do personagem nos momentos de relação entre ambos, ingestão de bebida e relação também com a atriz que servia os mesmos. Ao final da canção, o cantor saia de cena também simulando embriaguez, deixando o personagem/boneco a sós para dar prosseguimento às cenas dramáticas, onde na sequencia do espetáculo se iniciaria exatamente a entrada das pessoas queixosas ao governador. A voz, ao voltar do cantor para a forma animada, vem também carregando a embriaguez que ambos adquiriram após as ações físicas e verbais (estas através da ária em homenagem ao vinho) realizadas anteriormente, e a fala imediatamente após a saída do músico, mandem preparar os autos para a audiência, foi pronunciada por mim, ator/manipulador, de modo a denotar o estado ébrio do personagem/boneco. 


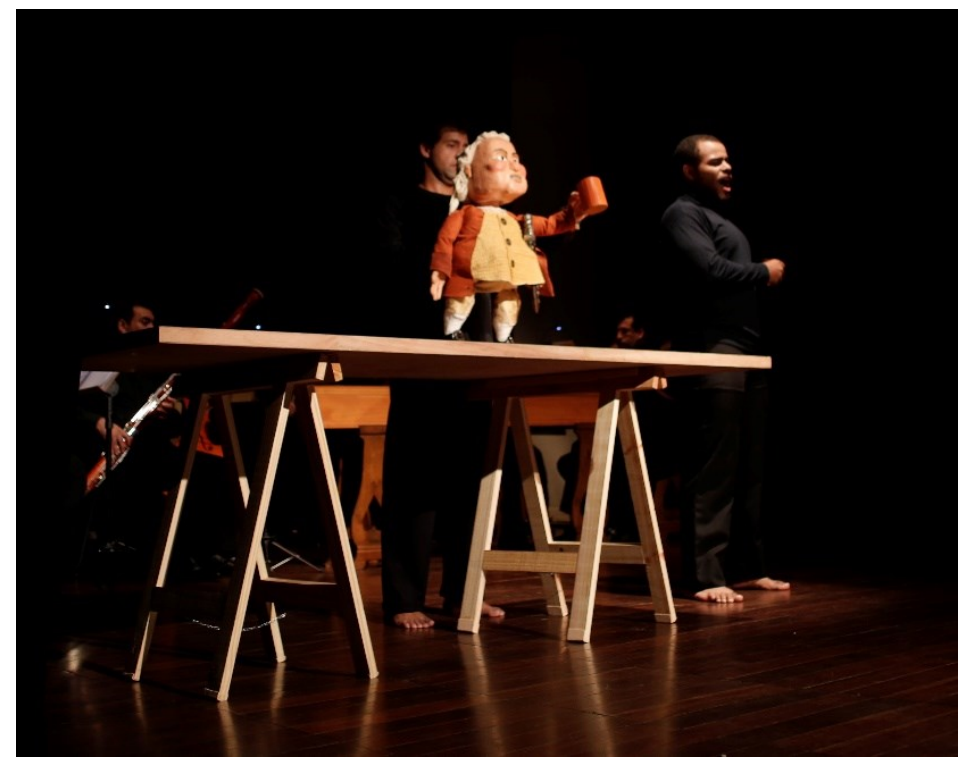

Figura 2 - Sancho Pança, manipulador e cantor Felix Bauer, apresentação de O Grande Governador da Ilha dos Lagartos no IV Simpósio Internacional de Musicologia em Pirenópolis/GO, 04/06/2014. Créditos: José de Alencar Melo (Zekhety)

Esta cena teve um processo bastante interessante de construção, principalmente por haver, como mencionado anteriormente, uma passagem de voz do boneco para o cantor que, assumindo a fala do personagem, trajando uma máscara semelhante ao rosto do mesmo, acabava por duplicar a imagem do Sancho Pança, tornando-o ao mesmo tempo boneco e barítono (uma vez que o registro de voz de Félix é o grave). Neste sentido, a cena com a voz cantada do personagem trouxe mais elementos para a construção da voz falada do mesmo, que passou também a carregar um leve tom despreocupado, certa languidez provocada pelo vinho, acentuando sua calma e parcimônia ao proferir seu excesso vocabular. Por outro lado, a partir do timbre vocal do cantor e da partitura vocal que já vinha construindo, tanto eu, atormanipulador, busquei reforçar no boneco-protagonista do espetáculo uma voz empostada, volumosa, com registro geral pendendo mais para o grave e, em apenas alguns momentos, acentuando registros mais agudos, quanto ele, cantor, também sofreu influências da construção vocal do personagem que havia sido feita por mim, uma vez que, ao executar a canção, Felix buscou incorporar à interpretação da ária algumas características do personagem, como seu ar bonachão e calmo, porém chegando ao enérgico nos momentos de vibração e entusiasmo em relação ao vinho. 
No que diz respeito a questão de como é formado o conjunto de técnicas vocais do ator, no momento da interpretação de um personagem, podemos dizer que:

\begin{abstract}
O processo de desenvolvimento técnico vocal para do ator envolve aspectos amplos pois o fenômeno da vocalidade no teatro, aplicação dos recursos vocais no processo criativo, se estrutura a partir de fundamentos fisiológicos, culturais e poéticos (técnicas e linguagens). No centro deste processo, o ator é o executor do código vocal e, por isso, concentra em si, naturalmente, o conteúdo a ser expresso, bem como os meios materiais da comunicação oral (ALEIXO, 2003, p. 1).
\end{abstract}

Sendo assim, podemos verificar que o processo de construção da voz do personagem Sancho-Pança, além de perpassar questões específicas da fisicalidade do ator-manipulador, teve como grande influência a linguagem adotada pela encenação, conjugando canto, música, cena e texto, num amplo conjunto de estímulos poéticos para composição da interpretação com o boneco. Além disso, vale salientar ainda que, no que diz respeito à questão da projeção vocal e ressonância, o diretor do espetáculo, Kleber Damaso, orientou todos os atores-manipuladores para que, no momento de suas falas, usassem o corpo do boneco como uma espécie de caixa de ressonância, dirigindo suas vozes para os bonecos, fazendo com que as mesmas chegassem até o público atravessando a materialidade da forma animada.

Voltando nossa discussão às vanguardas teatrais do início do século $X X$, veremos que a ideia do Ator-marionete já anteriormente levantada pelas experiências do russo Meierhold encontrou forte defesa a partir das teorias do britânico Edward Gordon Craig. Entretanto:

\footnotetext{
Na concepção de Craig sobre as marionetes, não há lugar para a voz. E este aspecto da linguagem tem repercussões no desenvolvimento, depois da $2 \underline{a}$ Guerra mundial, de um Teatro de Animação fortemente calcado na imagem. Craig deu primazia ao sentido da visão por meio do enaltecimento do movimento em detrimento do aspecto vocal. Certamente não podemos considerar sua visão como um caso isolado; ela também está dentro de um contexto maior, visto que o século XX é considerado como um século de imagens (IRLANDINI, 2013, p. 40).
}

Sendo assim, podemos observar que a voz, na concepção de alguns teatrólogos que advogavam por um ator que se assemelhasse, em sua fisicalidade, a uma marionete, era um elemento relegado ao segundo plano, interessando-lhes, 
prioritariamente, a movimentação física do ator e a visualidade que esta fisicalidade geraria na plástica geral da cena. Pensando neste aspecto, podemos então perceber que, no teatro de marionetes propriamente dito, ou Teatro de Formas Animadas, nomenclatura que temos usado neste artigo, a voz no trabalho de manipulação também acaba muitas vezes colocada em um patamar de inferioridade em relação a manipulação do boneco ou objeto.

Segundo Irlandini (2013), são amplas as possibilidades vocais nos diferentes espetáculos de Teatro de Animação, como por exemplo a característica de poder fazer várias vozes, o uso de aparelhos que modificam a voz, o canto, uso de línguas inexistentes e textos narrados/ dialogados em cena. Entretanto, analisando a cena atual, por um lado, grande parte dos espetáculos de Teatro de Formas Animadas não perfaz um trabalho que valorize os aspectos e, por outro, várias experiências abolem a voz da cena. A voz como linguagem artística é relegada a segundo plano em ambas as situações - nos primeiros, submetida a ser mero veículo semântico do texto, e nos segundos, emudecida ou reduzida ao mínimo.

Todavia, tendo como eixo o espetáculo $O$ Grande..., podemos perceber que o trabalho vocal, ao contrário, ganhou uma grande ênfase, tanto pelo fato de a montagem ter como ponto de partida um texto dramático e suas indicações como base para a criação cênica, quanto por incorporar a textualidade/vocalidade à interpretação/manipulação das formas animadas, uma vez que o processo de construção da gestualidade do ator-manipulador e, por conseguinte, da gestualidade do boneco, deu-se de forma bastante interligada ao processo de construção da partitura vocal do mesmo.

Segundo Fernando Aleixo, a relação entre corpo e voz é indissolúvel, uma vez que:

[...] a preparação vocal do ator deve adotar procedimentos metodológicos específicos, e fornecer referências para o estabelecimento de correspondências entre o aprimoramento dos aparatos físico e vocal e a aquisição de uma propriedade para a aplicação técnica da voz na composição, objetivando a conscientização e potencialização de seus 
recursos de expressão. Trata-se de uma trajetória a ser percorrida, respeitando as características psico-físicas do indivíduo, para uma compreensão corporal do processo de produção da voz e das suas possibilidades de empenho no desenvolvimento da vocalidade poética.

Assim, considerando a voz como corpo - dimensão orgânica que dará plenitude aos potenciais do ator, poderemos vislumbrar conquistas sensíveis no contexto da vocalidade no teatro (ALEIXO, 2002, p. 1)

Outra questão que merece ser apontada como modelo no que diz respeito ao processo entrelaçado entre a construção da gestualidade e da oralidade da forma animada, prende-se ao fato de que, a partir do advento de uma voz lânguida, calma e persuasiva, a movimentação física de Sancho passou também a cada vez mais incorporar uma leveza, uma suavidade, com movimentos contínuos, redondos, tornando a partitura física do personagem uma espécie de "dança” na maior parte do tempo. Mesmo seu caminhar, como já citado, a partir do ângulo de abertura de suas pernas, pôde ganhar um certo balanço no qual, enquanto a minha mão direita, que manipulava a cabeça do boneco, projetava o quadril e perna direta do mesmo à frente, a mão esquerda, segurando a parte de trás da perna esquerda do objeto, dava o passo seguinte, perfazendo uma caminhada que partia do giro do eixo do quadril do mesmo, reforçando ainda mais sua circularidade.

Circular, também, pode ser considerada a maioria dos longos textos emitidos pelo ator-manipulador, principalmente por ressaltar as vogais quando da articulação das palavras, alongando-as em diversos momentos, tornando o falar do boneco semelhante a um cantar, suavizando sua partitura vocal e, metaforicamente, atingindo os ouvidos dos outros personagens como um canto encantatório de sereia. Além das palavras, as onomatopeias, gritos e suspiros do personagem, em sua maioria, procuravam seguir esta mesma direção, e penso que um estudo exclusivo sobre este tipo de texto no teatro de formas animadas, carregado de subtexto, pois deixa claro ao espectador várias intenções da personagem, mereceria a atenção por parte de pesquisadores desta modalidade teatral. Vale complementar, ainda, que em outros trechos do espetáculo, onde o falar tornava-se mais ríspido e imperativo, com ênfase maior nas consoantes, a gestualidade do boneco procurava também seguir este caminho, com ações mais diretas, fortes e retilíneas. 
Dito isto, podemos afirmar que o processo de construção do espetáculo deu-se de forma bastante interligada entre diretores, músicos, atores-manipuladores e cantores, utilizando-se de um texto do século XVIII, adaptado e atualizado em sua linguagem predominantemente para a época atual, porém mantendo muitas expressões que se remetem àquele universo português quando da primeira encenação realizada pelo dramaturgo em Lisboa. Se a arte de interpretação/manipulação com formas animadas demanda habilidades específicas do ator, como técnicas de operação da forma animada, além da construção de uma partitura vocal que, partindo do ator, pretende dar voz ao objeto, a introdução de elementos como, no caso desta montagem, a música e o canto, abre frentes de investigações mais instigantes e promissoras do ponto de vista do desenvolvimento de novas habilidades de manipulação, concomitante à composição estética da cena que, congregando diferentes formas artísticas, se enriquece em sua força e pluralidade. Há ainda outras cenas deste espetáculo que merecem maiores reflexões, podendo ser fruto de futuros trabalhos que se detenham sobre elas, principalmente com a possibilidade de também nos utilizarmos da análise fílmica para este intento, uma vez que no ano de 2015 houve o lançamento de um DVD que contém não só o espetáculo na íntegra, como todo o making of do processo de construção do mesmo, o que certamente enriquecerá ainda mais os campos de investigações das áreas de teatro de formas animadas, manipulação de bonecos e intepretação teatral.

\section{REFERÊNCIAS}

ALEIXO, Fernando. Corporeidade da Voz - O Teatro Transcende. N. 12. Blumenau: FURB, Divisão de Promoções Culturais, 2003.

AMARAL, Ana Maria. Teatro de Animação. Cotia/SP: Ateliê Editorial, 2007.

BUENO, Kleber. Preâmbulo. In: SOUZA et. al, Ana Guiomar Rêgo. O Grande Governador da Ilha dos Lagartos: práticas de pesquisa e criação em artes. Goiânia: Editora UFG, 2015. p. 13-18. 
THAIS, Maria. Na Cena do Dr. Dapertutto. São Paulo: Perspectiva, 2009.

IRLANDINI, Isabella Azevedo. A Voz no Teatro de Animação: Artificialidade e Síntese Vocal. Florianópolis: Programa de Pós-Graduação em Teatro da UDESC, 2013. Dissertação de Mestrado. 